University of Wollongong

Research Online

Australian Institute for Innovative Materials -

Papers

Australian Institute for Innovative Materials

$1-1-2015$

\title{
Manganese dioxide-anchored three-dimensional nitrogen-doped graphene hybrid aerogels as excellent anode materials for lithium ion batteries
}

\author{
Zhu Yin Sui \\ University of Wollongong \\ Caiyun Wang \\ University of Wollongong, caiyun@uow.edu.au \\ Kewei Shu \\ University of Wollongong, ks323@uowmail.edu.au \\ Quan-Sheng Yang \\ National Center for Nanoscience \& Technology \\ Yu Ge \\ University of Wollongong, yg711@uowmail.edu.au
}

See next page for additional authors

Follow this and additional works at: https://ro.uow.edu.au/aiimpapers

Part of the Engineering Commons, and the Physical Sciences and Mathematics Commons

Research Online is the open access institutional repository for the University of Wollongong. For further information contact the UOW Library: research-pubs@uow.edu.au 


\title{
Manganese dioxide-anchored three-dimensional nitrogen-doped graphene hybrid aerogels as excellent anode materials for lithium ion batteries
}

\author{
Abstract \\ The capacity of manganese dioxide $\left(\mathrm{MnO}_{2}\right)$ deteriorates with cycling due to the irreversible changes \\ induced by the repeated lithiation and delithiation processes. To overcome this drawback, $\mathrm{MnO}_{2} / \mathrm{nitrogen}$ - \\ doped graphene hybrid aerogels (MNGAs) were prepared via a facile redox process between $\mathrm{KMnO}_{4}$ and \\ carbon within nitrogen-doped graphene hydrogels. The three-dimensional nitrogen-doped graphene \\ hydrogels were prepared and utilized as matrices for $\mathrm{MnO}_{2}$ deposition. The MNGAs- 120 obtained after a \\ deposition time of 120 min delivered a very high discharge capacity of $909 \mathrm{~mA} \mathrm{~h} \mathrm{~g}^{-1}$ after 200 cycles at a \\ current density of $400 \mathrm{~mA} \mathrm{~g}^{-1}$, in sharp contrast to only 280 and $70 \mathrm{~mA} \mathrm{~h} \mathrm{~g}^{-1}$ delivered from nitrogen- \\ doped graphene aerogels and $\mathrm{MnO}_{2}$. This discharge capacity is superior to that of the previously reported \\ $\mathrm{MnO}_{2}$ /carbon based hybrid materials. This material also exhibited an excellent rate capability and cycling \\ performance. Its superior electrochemical performance can be ascribed to the synergistic interaction \\ between uniformly dispersed $\mathrm{MnO}_{2}$ particles with high capacity and the conductive three-dimensional \\ nitrogen-doped graphene network with a large surface area and an interconnected porous structure.

\section{Keywords} \\ materials, anode, excellent, aerogels, hybrid, graphene, doped, nitrogen, dimensional, lithium, three, \\ manganese, ion, batteries, anchored, dioxide

\section{Disciplines} \\ Engineering | Physical Sciences and Mathematics

\section{Publication Details} \\ Sui, Z., Wang, C., Shu, K., Yang, Q., Ge, Y., Wallace, G. G. \& Han, B. (2015). Manganese dioxide-anchored \\ three-dimensional nitrogen-doped graphene hybrid aerogels as excellent anode materials for lithium ion \\ batteries. Journal of Materials Chemistry A, 3 (19), 10403-10412.
}

\section{Authors}

Zhu Yin Sui, Caiyun Wang, Kewei Shu, Quan-Sheng Yang, Yu Ge, Gordon G. Wallace, and Bao Hang Han 


\section{Manganese dioxide-anchored three-dimensional nitrogen-doped graphene hybrid aerogels as excellent anode materials for lithium ion batteries}

Zhu-Yin Sui, ${ }^{\mathrm{a}, \mathrm{b}}$ Caiyun Wang, ${ }^{\mathrm{b}}$ Kewei Shu, ${ }^{\mathrm{b}}$ Quan-Sheng Yang, ${ }^{\mathrm{a}}$ Yu Ge, ${ }^{\mathrm{b}}$ Gordon G. Wallace, ${ }^{\text {,b }}$ Bao-Hang Han*, a

${ }^{a}$ CAS Key Laboratory of Nanosystem and Hierarchy Fabrication, National Center for Nanoscience and Technology, Beijing 100190, China

${ }^{b}$ Intelligent Polymer Research Institute, ARC Centre of Excellence for Electromaterials Science, AIIM Facility, Innovation Campus, University of Wollongong, Wollongong, NSW 2522, Australia.

Tel.: +8610 8254 5576. E-mail: hanbh@nanoctr.cn.

Tel.: +61 24221 3127. E-mail: gwallace@uow.edu.au. 


\section{Abstract}

The capacity of manganese dioxide $\left(\mathrm{MnO}_{2}\right)$ deteriorates with cycling due to the irreversible changes induced by the repeated lithiation and delithiation processes. To overcome this drawback, $\mathrm{MnO}_{2} /$ nitrogen-doped graphene hybrid aerogels (MNGAs) were prepared via a facile redox process between $\mathrm{KMnO}_{4}$ and carbon within nitrogen-doped graphene hydrogels. The three-dimensional nitrogen-doped graphene hydrogels were prepared and utilized as matrices for $\mathrm{MnO}_{2}$ deposition. The MNGAs-120 obtained after a deposition time of 120 min delivered a very high discharge capacity of $909 \mathrm{~mA} \mathrm{~h} \mathrm{~g}{ }^{-1}$ after 200 cycles at a current density of $400 \mathrm{~mA} \mathrm{~g}^{-1}$, in sharp contrast to only 280 and $70 \mathrm{~mA} \mathrm{~h} \mathrm{~g}{ }^{-1}$ delivered from nitrogen-doped graphene aerogels and $\mathrm{MnO}_{2}$. This discharge capacity is superior to that of the previously reported $\mathrm{MnO}_{2} /$ carbon based hybrid materials. This material also exhibited an excellent rate capability and cycling performance. Its superior electrochemical performance can be ascribed to the synergistic interaction between uniformly dispersed $\mathrm{MnO}_{2}$ particles with high capacity and the conductive three-dimensional nitrogen-doped graphene network with a large surface area and interconnected porous structure.

Keywords: Manganese Dioxide; Nitrogen-Doped Graphene; Porous Material; Aerogel; Lithium Ion Battery. 


\section{Introduction}

With the rapid development of portable electronic devices and electric vehicles, development of next generation rechargeable lithium ion batteries with high capacity and long cycling stability have attracted intensive interest. ${ }^{1,2}$ Graphite is a commonly used anode material due to its low cost, natural abundance and good cycling stability. However, it suffers from low theoretical capacity (372 $\mathrm{mA} \mathrm{h} \mathrm{g}^{-1}$ ), retarding the development of more advanced lithium ion batteries. ${ }^{3}$

Nanostructured transition metal oxides with a high theoretical specific capacity and low cost are gaining wide spread attention. ${ }^{4,5,6,7,8,9}$ Manganese dioxide $\left(\mathrm{MnO}_{2}\right)$ is a particularly promising anode material owing to the high theoretical capacity $(1230 \mathrm{~mA} \mathrm{~h} \mathrm{~g})^{-1}{ }^{10,11,12}$ However, the specific capacity, rate performance and cycling stability are still not satisfactory to date due to the low inherent conductivity and large volume changes during the charge/discharge processes. ${ }^{13}$ To overcome these obstacles, one common strategy is to prepare $\mathrm{MnO}_{2}$ nanocomposites within a carbon matrix, which can act as both a conductive network increasing the electrical conductivity and a volume buffer to alleviate internal stress. ${ }^{14,15,16,17,18}$ The use of three-dimensional (3D) well-connected porous networks provide an additional benefit by shortening the ion diffusion length. ${ }^{19,20,21}$ A greatly improved battery performance is expected from $\mathrm{MnO}_{2} /$ carbon composites with a porous structure.

Graphene aerogels have been widely investigated due to their large specific surface area, high electrical conductivity and 3D interconnected porous structure. ${ }^{22,23}$ For example, Wang et al. reported that $\mathrm{MnO}_{2}$ /graphene aerogel composites prepared using an electrochemical method exhibited excellent capacitive characteristics including large specific capacitance (410 $\mathrm{F} \mathrm{g}^{-1}$ at 2 
$\mathrm{mV} \mathrm{s}^{-1}$ ), high rate capability and good cycling stability. ${ }^{23}$ The use of nitrogen-doped graphene aerogel can further enhance electrochemical performance. ${ }^{24,25}$ The presence of nitrogen atoms at the carbon surface can alter the electronic performance and provide more active sites. ${ }^{26,27}$ For example, Tan et al. prepared a tin oxide/nitrogen doped graphene aerogel composites using a hydrothermal method, which displayed a remarkable lithium storage capacity of $1100 \mathrm{~mA} \mathrm{~h} \mathrm{~g}^{-1}$ after 100 cycles at a current density of $200 \mathrm{~mA} \mathrm{~g}{ }^{-1} \cdot{ }^{28}$ Yin et al. reported that iron nitride $\left(\mathrm{Fe}_{x} \mathrm{~N}\right) /$ nitrogen doped graphene aerogel composites obtained from a hydrothermal method displayed an excellent catalytic activity in oxygen reduction reaction. ${ }^{29}$ However, the work on $\mathrm{MnO}_{2} /$ nitrogen-doped graphene aerogel composites has not been reported for lithium ion batteries to date.

In this work, we reported the fabrication of $\mathrm{MnO}_{2} /$ nitrogen-doped graphene hybrid aerogel composites (MNGAs) via an easy redox reaction between $\mathrm{KMnO}_{4}$ and carbon within nitrogen-doped graphene hydrogels (NGHs) for the first time. The as-prepared MNGAs as anode materials display a very high discharge capacity of $909 \mathrm{~mA} \mathrm{~h} \mathrm{~g}^{-1}$ after 200 cycles at a current density of $400 \mathrm{~mA} \mathrm{~g}^{-1}$. This result is superior to that previously reported $890 \mathrm{~mA} \mathrm{~h} \mathrm{~g}^{-1}$ at $100 \mathrm{~mA}$ $\mathrm{g}^{-1}$ for graphene-wrapped $\mathrm{MnO}_{2}$-graphene nanoribbons, ${ }^{30} 801 \mathrm{~mA} \mathrm{~h} \mathrm{~g}^{-1}$ after 50 cycles at $200 \mathrm{~mA}$ $\mathrm{g}^{-1}$ for $\mathrm{MnO}_{2} /$ carbon nanotube nanocomposite ${ }^{31}$ and $495 \mathrm{~mA} \mathrm{~h} \mathrm{~g}^{-1}$ after 40 cycles at $100 \mathrm{~mA} \mathrm{~g}^{-1}$ for graphene/ $\mathrm{MnO}_{2}$ nanotubes. ${ }^{32}$ Our samples also display excellent cycling performance and high rate capability. Such excellent performance can be ascribed to the synergistic effects of uniformly dispersed $\mathrm{MnO}_{2}$ particles and the conductive three-dimensional porous nitrogen-doped graphene sheets. 


\section{Experimental section}

\section{Preparation of nitrogen-doped graphene hydrogels (NGHs)}

Graphite oxide was prepared using natural graphite as the starting material via a modified Hummers' method, as described in the previous reports. ${ }^{33,34}$ The NGHs were prepared by a hydrothermal method. In a typical procedure, $4 \mathrm{~mL}$ of ammonia solution (28 wt\%) was added to 18 $\mathrm{mL}$ of aqueous GO dispersion $\left(5 \mathrm{mg} \mathrm{mL}^{-1}\right)$, then the mixture was sealed in a Teflon-lined stainless-steel autoclave. Black hydrogels were formed after the mixture was heated at $180{ }^{\circ} \mathrm{C}$ for 12 h. The products, NGHs, were obtained after the black hydrogels were dialyzed to remove the impurities.

\section{Preparation of NGAs and MNGAs}

The $\mathrm{MnO}_{2} /$ nitrogen-doped graphene hybrid aerogel composites (MNGAs) were fabricated through a facile redox reaction between $\mathrm{KMnO}_{4}$ and carbon within NGHs. In a typical procedure, NGHs were immersed in a solution of $0.1 \mathrm{M} \mathrm{KMnO}_{4} / 0.1 \mathrm{M} \mathrm{Na}_{2} \mathrm{SO}_{4}$. The above mixture was vigorously shaken in a shaker at room temperature to promote the diffusion of $\mathrm{KMnO}_{4} / \mathrm{Na}_{2} \mathrm{SO}_{4}$ solution into NGHs and the spontaneous reaction between $\mathrm{KMnO}_{4}$ and carbon in $\mathrm{NGHs}$. After the reaction, the hybrid hydrogels were dialyzed with a great amount of deionized water for $48 \mathrm{~h}$. The final products, MNGAs, were obtained by freeze-drying the hybrid hydrogels for $24 \mathrm{~h}$ under vacuum. An immersion time of 30, 60 and 120 min was applied to control $\mathrm{MnO}_{2}$ loading. These samples were designated as MNGAs- $\mathrm{x}(\mathrm{x}=30,60$ and $120 \mathrm{~min})$.

For comparison, nitrogen-doped graphene aerogels (NGAs) and $\mathrm{MnO}_{2}$ were also prepared as 
control samples. $\mathrm{MnO}_{2}$ was obtained after MNGAs were calcinated at $400{ }^{\circ} \mathrm{C}$ for $6 \mathrm{~h}$ in air to remove the carbon component within the hybrid aerogel composites. NGAs were prepared by freeze-drying the NGHs for $24 \mathrm{~h}$ under vacuum prior to $\mathrm{MnO}_{2}$ deposition.

\section{Materials characterisation}

A field emission scanning electron microscope (S-4800, Hitachi Ltd., Japan) was used to obtain the scanning electron microscopy (SEM) images, conducted at an accelerating voltage of 6 kV. Transmission electron microscopy (TEM) and high-angle annular dark-field scanning transmission electron microscope (HAADF-STEM) images were collected on a Tecnai $\mathrm{G}^{2} 20$ S-TWIN microscope (FEI, U.S.A.) with an accelerating voltage of $200 \mathrm{kV}$. X-ray diffraction (XRD) data were measured by a Philips X'Pert PRO X-ray diffraction instrument with a Cu $\mathrm{K}_{\alpha}$ radiation generator. X-ray photoelectron spectroscopy (XPS) measurements were carried out on an ESCALab220i-XL electron spectrometer (VG Scientific Ltd., U.K.) using $300 \mathrm{~W}$ Al K $\mathrm{K}_{\alpha}$ radiation.

Thermal gravimetric analysis (TGA) was operated on a Pyris Diamond thermogravimetric/differential thermal analyzer with a heating rate of $10^{\circ} \mathrm{C} \mathrm{min}^{-1}$ in air. Raman spectra were recorded on a Renishaw inVia Raman spectrometer (Renishaw plc, U.K.) with 514 $\mathrm{nm}$ laser as excitation source. Nitrogen adsorption-desorption tests were carried out at $77 \mathrm{~K}$ on a Micromeritics TriStar II 3020 surface area and porosity analyzer (Micromeritics Instrument Corporation, U.S.A.). The as-prepared samples were degassed under vacuum at $120{ }^{\circ} \mathrm{C}$ for $12 \mathrm{~h}$ prior to measurement. The nitrogen adsorption-desorption isotherms were used to assess pore properties, including Brunauer-Emmett-Teller (BET) specific surface area, pore size distribution and pore volume. 


\section{Electrochemical measurements}

The electrode was composed of active material (80 wt\%), carbon black (10 wt\%) and polyvinylidene fluoride (10 wt\%) in $N$-methyl-2-pyrrolidinone. The resultant slurry was coated onto a copper foil substrate and dried at $80{ }^{\circ} \mathrm{C}$ for $12 \mathrm{~h}$ in a vacuum oven. The mass loading of electrode materials was typically in the range of $1.5-2 \mathrm{mg} \mathrm{cm}^{-2}$. The electrode was assembled into LR 2032 type coin cells coupled with a lithium metal in a 1 M LiPF 6 electrolyte (1:1 v\% ethylene carbonate and dimethyl carbonate). The galvanostatic charge/discharge tests were performed over a potential range of $0.005-3.0 \mathrm{~V}$ (vs. $\mathrm{Li} / \mathrm{Li}^{+}$) on a LAND CT2001A battery test system (Wuhan Jinnuo Electronics Co. Ltd. China). Cyclic voltammetry was measured using a Solartron SI 1287 between 0.0 to $3.0 \mathrm{~V}$ (vs. $\mathrm{Li} / \mathrm{Li}^{+}$) at a scan rate of $0.2 \mathrm{mV} \mathrm{s}$. Electrochemical impedance spectroscopy (EIS) measurements were carried out on a Gamry EIS 3000 system at open circuit potential over the frequency range of $0.01 \mathrm{~Hz}$ to $100 \mathrm{kHz}$.

\section{Results and discussion}

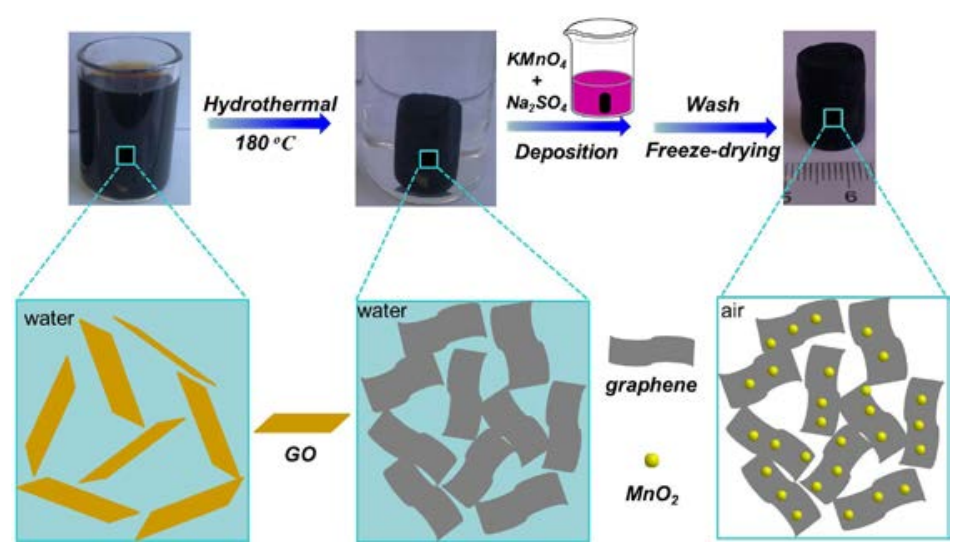

Fig. 1 Schematic procedures to prepare MNGAs.

NGHs were obtained by heating a mixture containing aqueous GO dispersion and ammonia 
sealed in a Teflon-lined stainless-steel autoclave at $180{ }^{\circ} \mathrm{C}$ for $12 \mathrm{~h}$, as illustrated in Fig. 1. Ammonia was the nitrogen source used to dope graphene sheets at high hydrothermal temperature. $^{35,36}$ The formation of NGHs was driven by hydrogen bonding, $\pi-\pi$ stacking and hydrophobicity interactions between nitrogen-doped graphene sheets. ${ }^{35,37}$ Subsequently NGHs were placed into the $\mathrm{KMnO}_{4} / \mathrm{Na}_{2} \mathrm{SO}_{4}$ precursor solution and $\mathrm{MnO}_{2}$ was formed via the spontaneous redox deposition: $4 \mathrm{KMnO}_{4}+3 \mathrm{C}+\mathrm{H}_{2} \mathrm{O}=4 \mathrm{MnO}_{2}+\mathrm{K}_{2} \mathrm{CO}_{3}+2 \mathrm{KHCO}_{3}{ }^{38,39}$ The final products, MNGAs were obtained by freeze-drying of the hybrid hydrogels under vacuum for $24 \mathrm{~h}$. The loading amount of $\mathrm{MnO}_{2}$ was controlled by the immersion and reaction time. It was 16.1, 27.3 and 42.5 wt\% in MNGAs-30, MNGAs-60 and MNGAs-120, respectively (estimated from the TGA curves in Fig. S1).
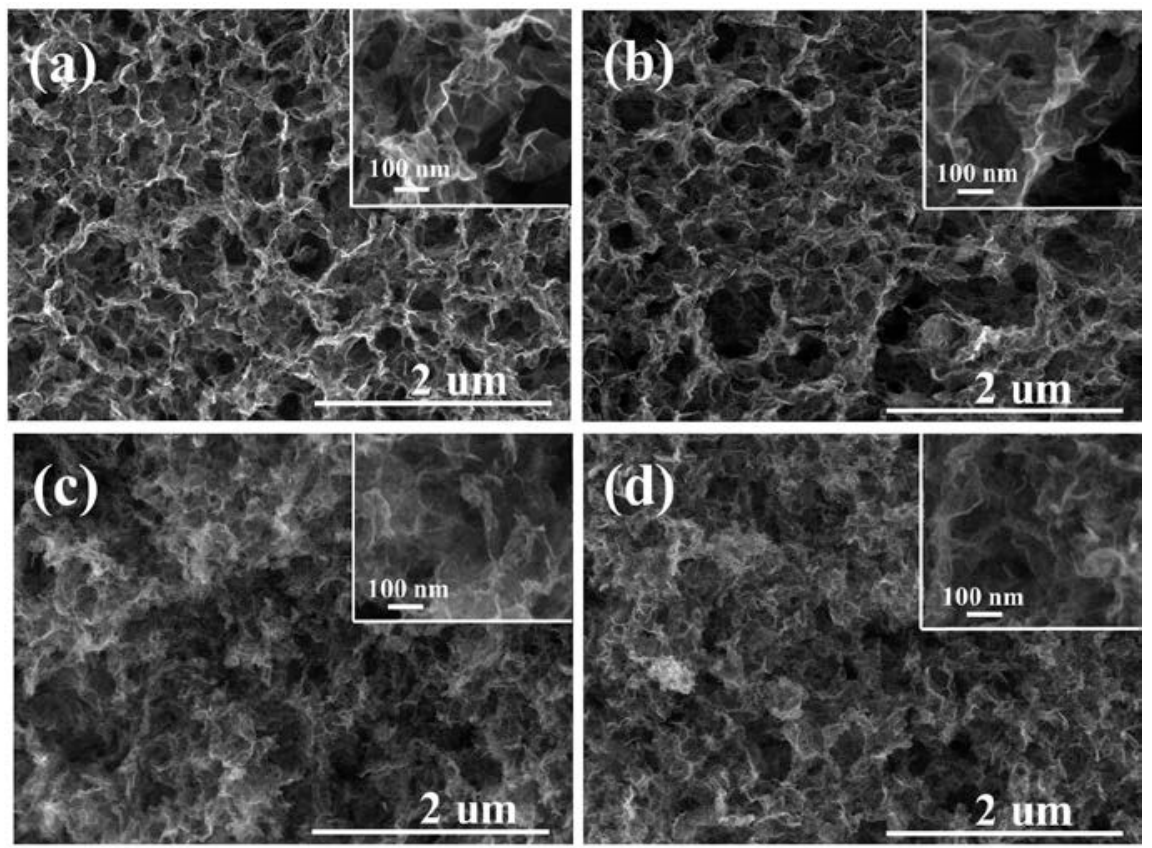

Fig. 2 SEM images of NGAs (a), MNGAs-30 (b), MNGAs-60 (c) and MNGAs-120 (d). Insets: SEM images at higher magnification.

NGAs exhibit a 3D network structure with interconnected pores (Fig. 2a). This porous 
structure was maintained when the $\mathrm{MnO}_{2}$ nanoparticles deposition time was 30 min (MNGA-30, Fig. 2b). When this increased to 60 and $120 \mathrm{~min}$, the interconnected porous structure became less well defined. However, the porous structure can be observed at higher magnification (insets of Fig. 2c and 2d). Interestingly, no large $\mathrm{MnO}_{2}$ particles or aggregates were observed at high magnification even for the sample MNGAs-120 with $42.5 \mathrm{wt} \%$ of $\mathrm{MnO}_{2}$.

The porous characteristics of NGAs and MNGAs were further studied by nitrogen adsorption-desorption measurements (Fig. 3). Both MNGAs and NGAs possess type IV adsorption-desorption isotherms with type H3 hysteresis loops (Fig. 3a), indicating that mesoporosity and slit-shaped pores exist in these hybrid aerogels. The BET specific surface area of these samples decreased with the increased $\mathrm{MnO}_{2}$ loading. It was $820 \mathrm{~m}^{2} \mathrm{~g}^{-1}$ for NGAs, which became 640 for MNGAs-30, 590 for MNGAs-60 and $490 \mathrm{~m}^{2} \mathrm{~g}^{-1}$ for MNGAs-120. The pore volume decreased as well, from $1.61 \mathrm{~cm}^{3} \mathrm{~g}^{-1}$ to $1.34,1.25$ and $1.12 \mathrm{~cm}^{3} \mathrm{~g}^{-1}$, respectively. The decrease in the specific surface area and pore volume can be attributed to the increased loading amount of $\mathrm{MnO}_{2}$ nanoparticles within the hybrid aerogel. According to Barret-Joyner-Halenda adsorption pore size distributions (Fig. 3b), most pore volume of NGAs, MNGAs-30, MNGAs-60, and MNGAs-120 lie in the 2-40 nm region and the main peak located at $\sim 2.3 \mathrm{~nm}$. The formation of these nanosized pores can be ascribed to the 3D assembly of $2 \mathrm{D}$ graphene sheets during hydrothermal treatment, which has been observed previously. ${ }^{20,40}$ 

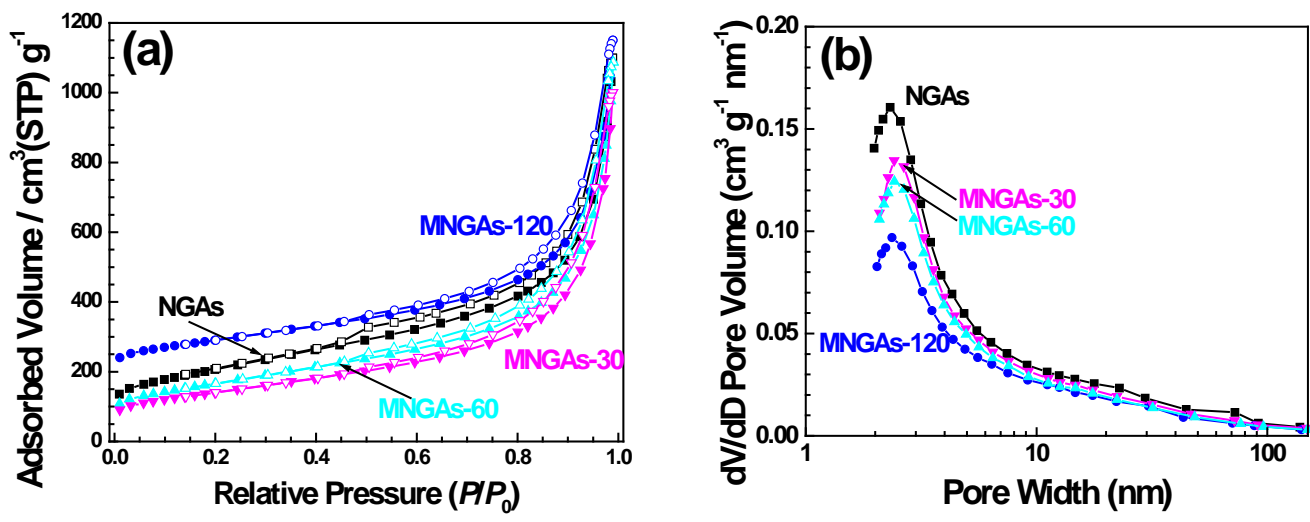

Fig. 3 Nitrogen sorption isotherms (a) and Barret-Joyner-Halenda adsorption pore size distributions (b) of NGAs, MNGAs-30, MNGAs-60 and MNGAs-120 (solid symbols: adsorption; empty symbols: desorption). The isotherm of MNGAs-120 was offset by 150 units for clarity.

The successful deposition of $\mathrm{MnO}_{2}$ particles onto nitrogen-doped graphene sheets can be revealed with TEM images (Fig. 4a-d). More $\mathrm{MnO}_{2}$ nanoparticles can be observed on the nitrogen-doped graphene sheets with the increasing immersion and reaction time of NGHs in $\mathrm{KMnO}_{4} / \mathrm{Na}_{2} \mathrm{SO}_{4}$ solution. Also no large aggregates can be found. The size of $\mathrm{MnO}_{2}$ particles was 4-8 nm (Fig. 4e). The lattice spacing of $\mathrm{MnO}_{2}$ nanoparticles was measured to be $2.4 \AA$ (Fig. 4f), which corresponded to that of (006) planes of birnessite $\mathrm{MnO}_{2} \cdot{ }^{41}$ MNGAs-120 sample was chosen to investigate the dispersibility of $\mathrm{MnO}_{2}$ nanoparticles within nitrogen-doped graphene matrices. A 3D porous network structure was observed (Fig. $4 \mathrm{~g}$ and $\mathrm{h}$ ), which is consistent with the SEM results. All the elements of $\mathrm{C}, \mathrm{N}, \mathrm{O}$ and $\mathrm{Mn}$ displayed a uniform distribution (Fig. 4i-1), further proving that $\mathrm{MnO}_{2}$ nanoparticles were uniformly anchored onto the nitrogen-doped graphene sheets. 

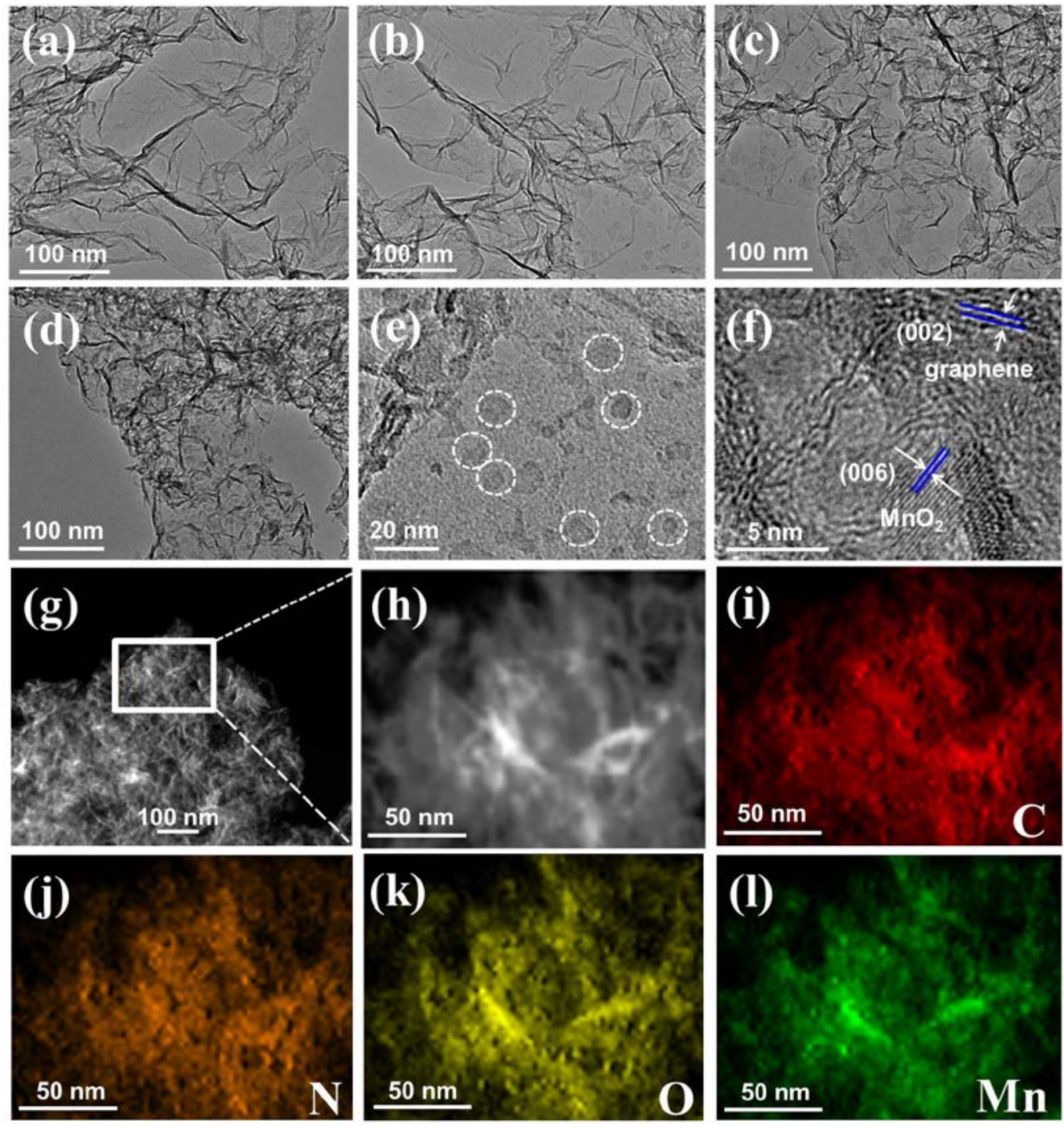

Fig. 4 TEM images of NGAs (a), MNGAs-30 (b), MNGAs-60 (c) and MNGAs-120 (d); TEM images of MNGAs-120 at high magnifications (e and f); HAADF-STEM image of MNGAs-120 at low (g) and high (h) magnifications; EDS mapping of C (i), N (j), O (k) and Mn (l).

The introduction of $\mathrm{MnO}_{2}$ nanoparticles into nitrogen-doped graphene networks can also be detected using X-ray diffraction method. A broad peak centered at around $24^{\circ}$ (ca. $0.37 \mathrm{~nm}$ of interlayer spacing) is observed for NGAs (Fig. 5a), indicative of the restacking of nitrogen-doped graphene sheets occurred during the freeze-drying process, which is in accordance with the 
previous reports. ${ }^{35}$ After the incorporation of $\mathrm{MnO}_{2}$, the peak at around $24^{\circ}$ becomes weaker and two new peaks appear at around $36.8^{\circ}$ and $65.7^{\circ}$. These two peaks correspond to the (006) and (119) peaks of $\mathrm{MnO}_{2}$ (JCPDF 18-0802), which further confirms the successful introduction of $\mathrm{MnO}_{2}$ nanoparticles.

The chemical composition and more structural information were revealed by XPS and Raman spectroscopy. XPS reveals the presence of C, O and N in NGAs. An additional signal attributed to manganese (Mn 2p) appears in the MNGA samples (Fig. 5b), evidence of $\mathrm{MnO}_{2}$ deposition onto the nitrogen-doped graphene sheets. The nitrogen content in NGAs, MNGAs-30, MNGAs-60, and MNGAs-120 is 8.1, 7.1, 6.6, and 6.1 atom \%, respectively. The N 1s spectrum of MNGAs-120 (Fig. 5c) can be deconvoluted into three peaks, pyridinic (398.7 eV), pyrrolic (399.9 eV) and quaternary nitrogen $(401.8 \mathrm{eV}){ }^{42}$ In the high-resolution XPS spectrum of Mn 2p (Fig. 5d),

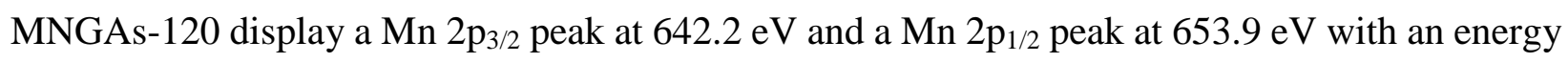
separation of $11.7 \mathrm{eV}$. These two peaks of $\mathrm{Mn} 2 \mathrm{p}$ are consistent with the previously reported data. ${ }^{43}$ NGAs and MNGAs display two strong characteristic peaks of carbonaceous materials in Raman spectra (Fig. 5e), $D$-band $\left(\approx 1350 \mathrm{~cm}^{-1}\right)$ and $G$-band $\left(\approx 1590 \mathrm{~cm}^{-1}\right)$, confirming the presence of graphene sheets. ${ }^{44}$ Two obvious peaks (around 570 and $650 \mathrm{~cm}^{-1}$ ) can be found in the low wavenumber region for all MNGAs samples. They correspond to the vibrations of oxygen ions in the manganate lattice, further confirming the incorporation of $\mathrm{MnO}_{2}$ nanoparticles. ${ }^{45,46}$ 

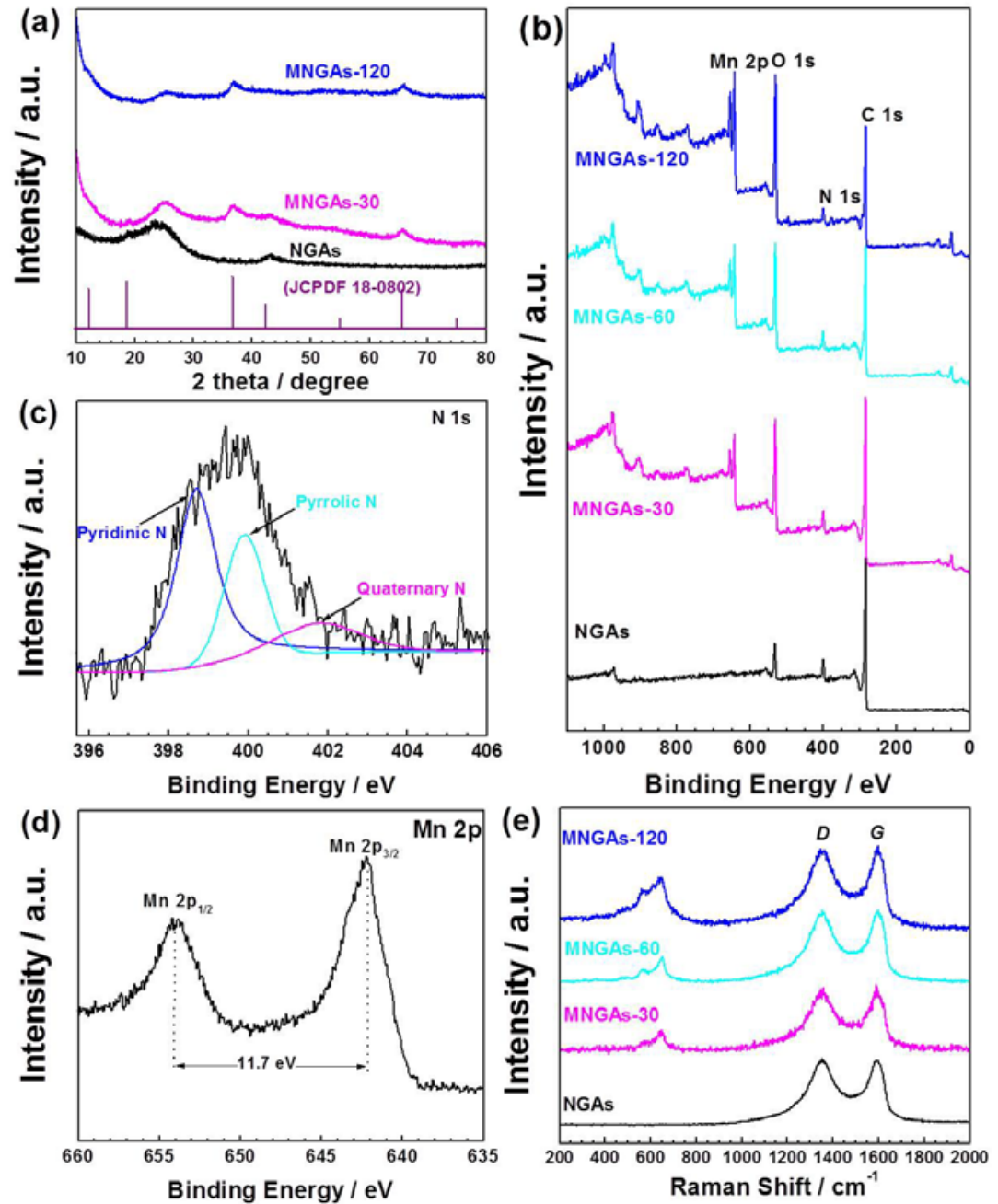

Fig. 5 XRD patterns (a) and XPS survey scan spectra (b) of NGAs and MNGAs; N 1s (c) and Mn 2p XPS spectra (d) of MNGAs-120; (e) Raman spectra of NGAs and MNGAs.

The electrochemical process of the lithiation and delithiation of NGAs and MNGAs was investigated using cyclic voltammetry at a scan rate of $0.2 \mathrm{mV} \mathrm{s}^{-1}$. An irreversible reduction peak appears at around $0.5 \mathrm{~V}$ in the first cycle for all these samples (Fig. 6), and this is attributed to the formation of a solid electrolyte interphase (SEI) layer at the electrode surface. ${ }^{47,48}$ This peak disappears in the following cycles. Compared to NGAs, a sharp cathodic peak at around $0.3 \mathrm{~V}$ is observed for all the MNGAs samples. This is attributed to the reduction reaction of $\mathrm{MnO}_{2}\left(\mathrm{MnO}_{2}\right.$ 
$\left.+4 \mathrm{Li}^{+}+4 \mathrm{e}^{-} \rightarrow 2 \mathrm{Li}_{2} \mathrm{O}+\mathrm{Mn}\right)$. These MNGAs electrodes display two anodic peaks at 1.2 and 2.0 V. These two anodic peaks might be ascribed to two oxidation processes from $\mathrm{MnO}_{2}, \mathrm{Mn}^{0}$ to $\mathrm{Mn}^{2+}$ and $\mathrm{Mn}^{2+}$ to $\mathrm{Mn}^{4+} \cdot 49$
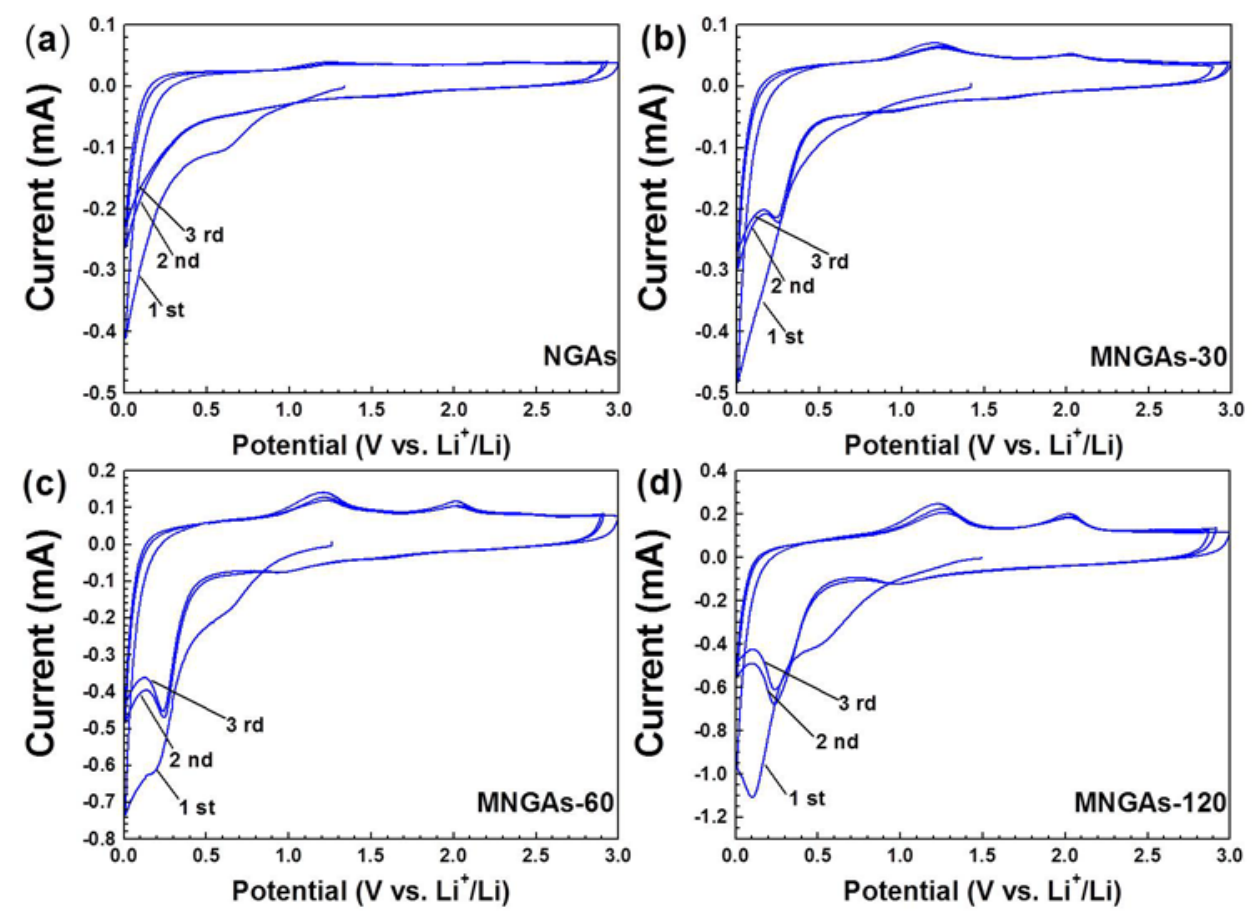

Fig. 6 (a) Cyclic voltammograms (CV) of the first three discharge/charge cycles for NGAs (a), MNGAs-30 (b), MNGAs-60 (c) and MNGAs-120 (d) at a scan rate of $0.2 \mathrm{mV} \mathrm{s}^{-1}$ between 0.0-3.0 V.

The first three discharge/charge cycles for NGAs and MNGAs at $100 \mathrm{~mA} \mathrm{~g}^{-1}$ are illustrated in Fig. 7a-d. The initial discharge capacity of NGAs, MNGAs-30, MNGAs-60 and MNGAs-120 is 1090, 924, 1026 and $1172 \mathrm{~mA} \mathrm{~h} \mathrm{~g}^{-1}$. Their initial charge capacity is 608, 648, 786 and $937 \mathrm{~mA} \mathrm{~h}$ $\mathrm{g}^{-1}$, corresponding to a Coulombic efficiency of $56 \%, 70 \%, 77 \%$ and $80 \%$. At the $3^{\text {rd }}$ cycle, the discharge capacity of NGAs, MNGAs-30, MNGAs-60 and MNGAs-120 is 567, 691, 775 and 941 mA h $\mathrm{g}^{-1}$, displaying a Coulombic efficiency of $92 \%, 91 \%, 95 \%$ and $96 \%$, respectively. The 
large capacity loss can be ascribed to the formation of SEI layer, which is in agreement with CV results. This clearly demonstrates that the discharge capacity and Coulombic efficiency are greatly improved after the incorporation of $\mathrm{MnO}_{2}$ nanoparticles into NGA matrices. The enhanced performance can be explained by the synergistic interaction between $\mathrm{MnO}_{2}$ nanoparticles and the conductive nitrogen-doped graphene network with an interconnected porous structure. The contribution from uniformly distributed $\mathrm{MnO}_{2}$ nanoparticles include additional high capacity and a spacer to present the sever restacking of graphene nanosheets. The 3D conductive nitrogen-doped graphene sheets can improve the poor conductivity of $\mathrm{MnO}_{2}$. The presence of nitrogen atoms is also beneficial to the storage capacity of lithium ions. ${ }^{27}$

The rate capability of MNGAs and NGAs was studied at different current density of 100, 200, 400, 600, 800, 1000 and $1500 \mathrm{~mA} \mathrm{~g}^{-1}$ (Fig. 7e). For $\mathrm{MnO}_{2}$ sample, it delivers an initial discharge capacity of $959 \mathrm{~mA} \mathrm{~h} \mathrm{~g}^{-1}$ at a current density of $100 \mathrm{~mA} \mathrm{~g}^{-1}$ and only remains $24 \mathrm{~mA} \mathrm{~h} \mathrm{~g}^{-1}$ at a current density of $1500 \mathrm{~mA} \mathrm{~g}^{-1}$ after 70 cycles, a $2.5 \%$ capacity retention. While for MNGAs samples, they show excellent rate capability compared to that observed for pure $\mathrm{MnO}_{2}$ or NGAs. NGAs, MNGAs-30, MNGAs-60 and MNGAs-120 electrodes show a discharge capacity of 461, 649, 716 and $1003 \mathrm{~mA} \mathrm{~h} \mathrm{~g}^{-1}$ at a current density of $100 \mathrm{~mA} \mathrm{~g}^{-1}$, respectively. The capacity turns to be $276,435,571$ and $846 \mathrm{~mA} \mathrm{~h} \mathrm{~g}^{-1}$ at a current density of $400 \mathrm{~mA} \mathrm{~g}^{-1}$, respectively. MNGAs-120 electrodes exhibit the highest discharge specific capacity and rate capability. The discharge/charge curves of NGAs, MNGAs-30, MNGAs-60, and MNGAs-120 electrodes at different current densities were also given in Fig. S2. It can still deliver a discharge capacity of $636 \mathrm{~mA} \mathrm{~h} \mathrm{~g}^{-1}$ at a current density of $1500 \mathrm{~mA} \mathrm{~g}^{-1}$, which is 3.9 times higher than that $\left(162 \mathrm{~mA} \mathrm{~h} \mathrm{~g}^{-1}\right)$ of NGAs. As 
the current density returns back to $100 \mathrm{~mA} \mathrm{~g}^{-1}$, MNGAs-120 electrodes deliver a discharge specific capacity of $1095 \mathrm{~mA} \mathrm{~h} \mathrm{~g}^{-1}$, slightly higher than the initial reversible capacity.
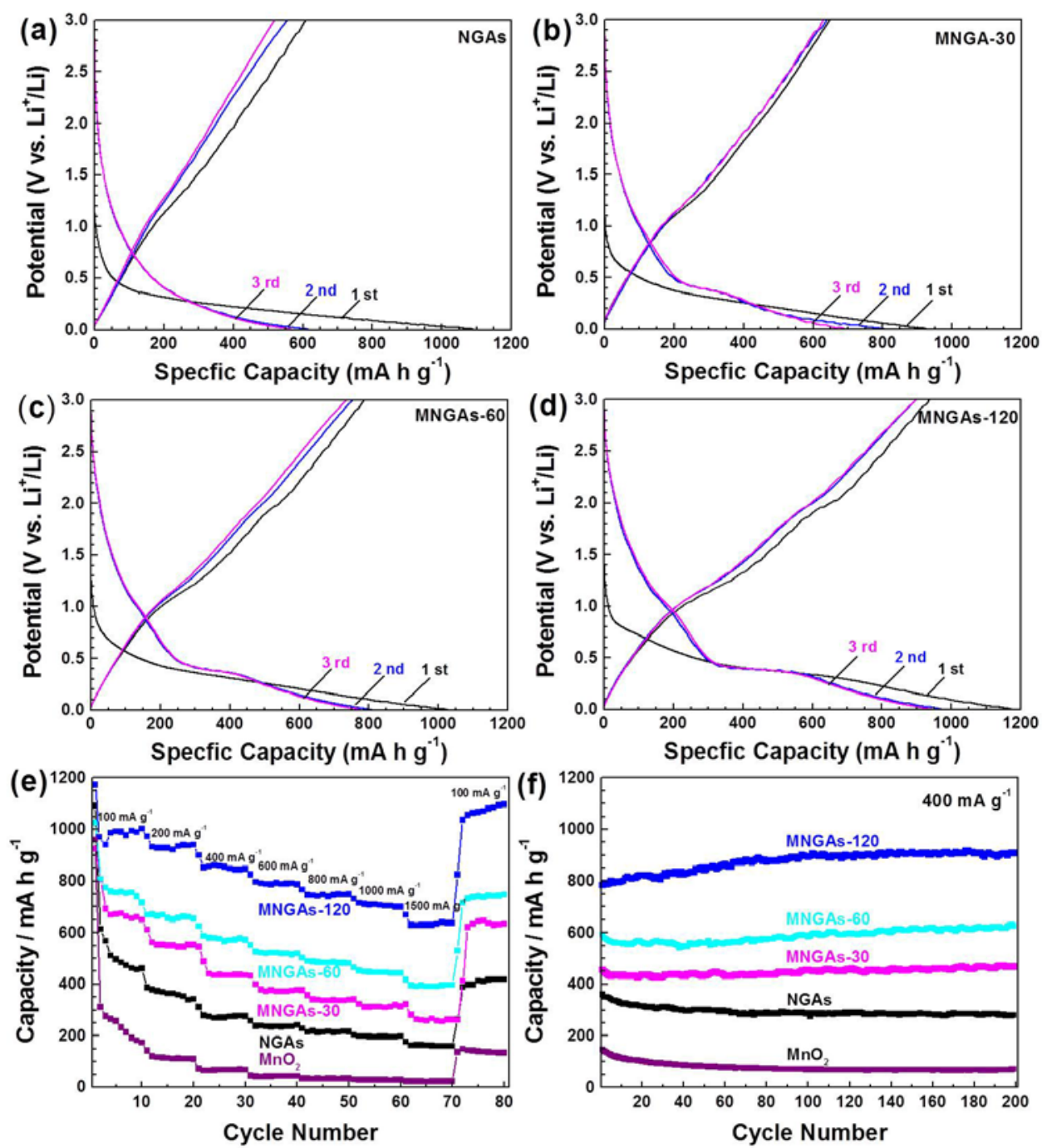

Fig. 7 The first three discharge/charge cycles of NGAs (a), MNGAs-30 (b), MNGAs-60 (c) and MNGAs-120 (d) at the current density of $100 \mathrm{~mA} \mathrm{~g}^{-1}$; (e) rate capacity curves of $\mathrm{NGAs} \mathrm{MnO}_{2}$ and MNGAs between $0.005 \mathrm{~V}$ and $3.0 \mathrm{~V}$ at various current densities; (f) capacity vs. cycle number curves of NGAs, $\mathrm{MnO}_{2}$ and MNGAs at the discharge current of $400 \mathrm{~mA} \mathrm{~g}^{-1}$. (Note: The first cycle is not included.)

The cycling performance of NGAs and MNGAs was tested at a current density of $400 \mathrm{~mA} \mathrm{~g}^{-1}$ 
(Fig. 7f). The discharge capacity of MNGAs increases with an increase of $\mathrm{MnO}_{2}$ loading. Their Coulombic efficiency approaches $100 \%$ after a few cycles (Fig. S3). For $\mathrm{MnO}_{2}$ sample, the reversible capacity was only $70 \mathrm{~mA} \mathrm{~h} \mathrm{~g}^{-1}$ after 200 cycles, a $48 \%$ capacity retention. This sharp capacity decay can be ascribed to the particle pulverization during the repeated lithiation and delithiation processes. MNGAs-30, MNGAs-60 and MNGAs-120 electrodes show a discharge capacity of 467, 627 and $909 \mathrm{~mA} \mathrm{~h} \mathrm{~g}^{-1}$ after 200 cycles, in sharp contrast to $\mathrm{MnO}_{2}\left(70 \mathrm{~mA} \mathrm{~h} \mathrm{~g}^{-1}\right.$ ) and NGA (280 $\mathrm{mA} \mathrm{h} \mathrm{g}{ }^{-1}$ ). This enhanced electrochemical performance suggests that nitrogen-doped graphene sheets in a porous structure can effectively alleviate the volume changes of $\mathrm{MnO}_{2}$ nanoparticles during the lithiation and delithiation processes. In addition, the presence of nitrogen can enhance the battery performance by introducing more defects. ${ }^{26}$ These defects are beneficial to the adsorption of lithium ions and the penetration of lithium ions into the interior of the electrode, thus increasing the storage capability of lithium. ${ }^{27}$ It is also noticed that the discharge capacity of MNGAs electrodes increased slightly with the cycling number. It can be explained that the electrolyte can accesses this composite in depth after the lithiation and delithiation processes and offer higher electrochemical activity. ${ }^{30}$

The EIS measurements were used to study the charge transport kinetics of $\mathrm{MnO}_{2}$ and hybrid aerogel composites. As shown in Fig. 8a, the Nyquist plots of $\mathrm{MnO}_{2}$ and MNGAs consist of a semicircle (high frequency region) attributed to the charge transfer resistance at the electrode/electrolyte interface and a straight line (low frequency region) related to lithium ions diffusion in the bulk materials. All MNGAs samples possess a much smaller semicircle than $\mathrm{MnO}_{2}$, indicating that 3D porous structure of nitrogen-doped graphene network can reduce the electron 
transfer resistance and enhance the ion and electron kinetics. It can be used to explain the improved electrochemical performance driven from those composites. It was also noticed that NGAs possess a much smaller semicircle than MNGAs-120. However, MNGAs-120 electrodes display much higher discharge capacity. The greatly improved capacity can be ascribed to the introduction and contribution of $\mathrm{MnO}_{2}$ with high theoretical capacity.

Fig. 8b shows the scheme of the possible structure for MNGAs electrodes. The significantly improved lithium storage capability, high-rate performance and cycling stability of MNGAs can be ascribed to the synergistic interaction between uniformly dispersed $\mathrm{MnO}_{2}$ particles and the 3D conductive nitrogen-doped graphene network. (1) The porous network of nitrogen-doped graphene sheets provides a mechanical support to alleviate the volume changes associated with $\mathrm{MnO}_{2}$ nanoparticles during the lithiation and delithiation processes. (2) The 3D connected graphene-based matrix can work as a conductive layer to reduce the charge transfer resistance, thus enhancing the ion and electron kinetics. (3) The open porous structure of MNGAs can facilitate easy access of electrolyte and also a shortened ion diffusion length. (4) Nitrogen-doping leads to more defects, which can provide more adsorption sites for lithium ions and also promote the penetration of lithium into the interior of the electrode. 

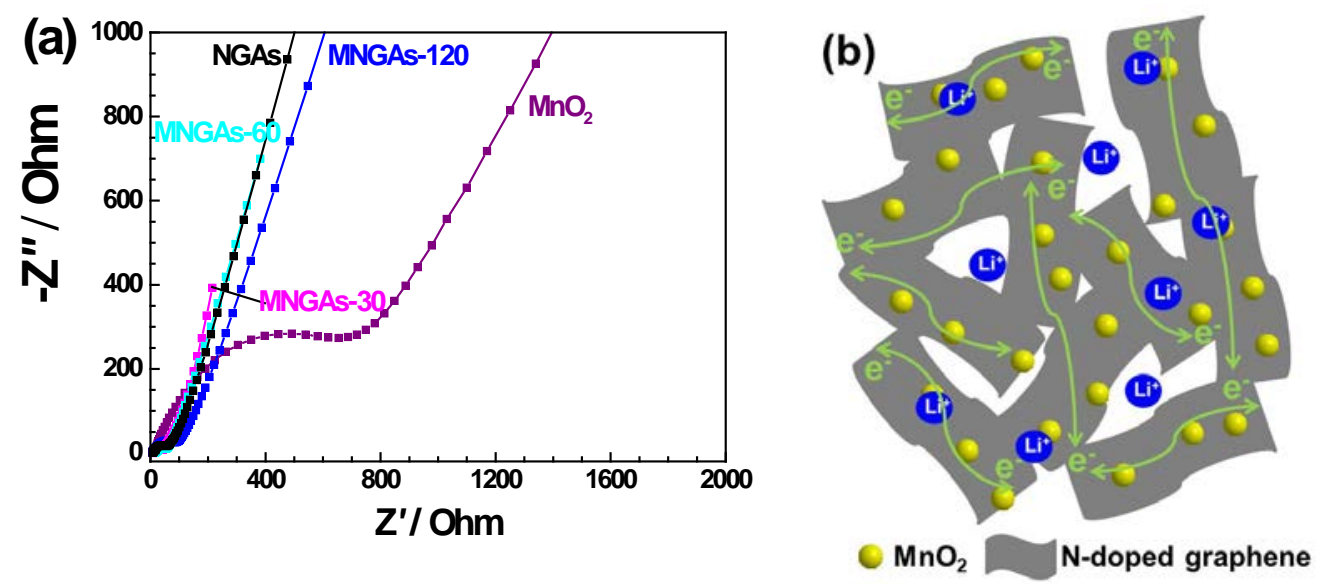

Fig. 8 (a) The electrochemical impedance spectra of NGA and MNGAs electrodes; and (b) schematic illustration of structure for MNGAs electrodes.

\section{Conclusions}

3D porous MNGAs have been prepared via a facile process involving $\mathrm{KMnO}_{4}$ and carbon from NGHs. $\mathrm{MnO}_{2}$ nanoparticles were incorporated into a 3D porous network of NGHs and were uniformly dispersed on nitrogen-doped graphene sheets. These samples possess a very high specific capacity, excellent rate performance and cycling stability compared to NGAs and $\mathrm{MnO}_{2}$ samples. Such superior electrochemical properties can be ascribed to the unique conductive 3D porous structure, which can not only alleviate the volume expansion of $\mathrm{MnO}_{2}$ nanoparticles but also enhance the charge transfer. The shortened ion diffusion path and enhanced electron transfer from nanosized $\mathrm{MnO}_{2}$ particles as well as nitrogen-doping contribute to the enhanced performance. Other inorganic nanoparticles might be incorporated into nitrogen-doped graphene aerogel through this facile method, such as $\mathrm{MoO}_{2}, \mathrm{Co}_{3} \mathrm{O}_{4}$ and $\mathrm{SnO}_{2}$. These hybrid aerogel composites may hold promise in the fields of supercapacitors, batteries and catalysis. 
Acknowledgements. The financial support of the Ministry of Science and Technology of China (Grant 2014CB932204) and the National Science Foundation of China (Grants no. 21374024 and 61261130092) is acknowledged. G. G. Wallace, C. Wang and Z.-Y. Sui thank the Australia Research Council (ARC) for financial support under the umbrella of ARC Centre of Excellence for Electromaterials Science.

Electronic supplementary information (ESI) available: TGA curves of MNGAs-30, MNGAs-60 and MNGAs-120 under air atmosphere; the discharge/charge curves of NGAs, MNGAs-30, MNGAs-60 and MNGAs-120 electrodes at different current densities (100, 200, 400, 600, 800, 1000 and $1500 \mathrm{~mA} \mathrm{~g}^{-1}$ ); Coulombic efficiency of NGAs, MNGAs-30, MNGAs-60 and MNGAs-120 at a current density of $400 \mathrm{~mA} \mathrm{~g}^{-1}$.

\section{References}

[1] C. Liu, F. Li, L.-P. Ma and H.-M. Cheng, Advanced materials for energy storage. Adv. Mater. 2010, 22 (8), E28-E62.

[2] Y. G. Guo, J. S. Hu and L. J. Wan, Nanostructured materials for electrochemical energy conversion and storage devices. Adv. Mater. 2008, 20 (15), 2878-2887.

[3] W. Y. Zhang, Y. Zen, N. Xiao, H. H. Hng and Q. Y. Yan, One-step electrochemical preparation of graphene-based heterostructures for Li storage. J. Mater. Chem. 2012, 22 (17), 8455-8461. [4] Z. S. Wu, W. C. Ren, L. Wen, L. B. Gao, J. P. Zhao, Z. P. Chen, G. M. Zhou, F. Li and H. M. Cheng, Graphene anchored with $\mathrm{Co}_{3} \mathrm{O}_{4}$ nanoparticles as anode of lithium ion batteries with enhanced reversible capacity and cyclic performance. ACS Nano 2010, 4 (6), 3187-3194. 
[5] P. Meduri, C. Pendyala, V. Kumar, G. U. Sumanasekera and M. K. Sunkara, Hybrid tin oxide nanowires as stable and high capacity anodes for Li-ion batteries. Nano Lett. 2009, 9 (2), 612-616. [6] Y. S. Hu, L. Kienle, Y. G. Guo and J. Maier, High lithium electroactivity of nanometer-sized rutile $\mathrm{TiO}_{2}$. Adv. Mater. 2006, 18 (11), 1421-1426.

[7] W. Y. Li, L. N. Xu and J. Chen, $\mathrm{Co}_{3} \mathrm{O}_{4}$ nanomaterials in lithium-ion batteries and gas sensors. Adv. Funct. Mater. 2005, 15 (5), 851-857.

[8] M. Yu, A. Wang, Y. Wang, C. Li and G. Shi, An alumina stabilized ZnO-graphene anode for lithium ion batteries via atomic layer deposition. Nanoscale 2014, 6 (19), 11419-11424.

[9] M. Zheng, D. Qiu, B. Zhao, L. Ma, X. Wang, Z. Lin, L. Pan, Y. Zheng and Y. Shi, Mesoporous iron oxide directly anchored on a graphene matrix for lithium-ion battery anodes with enhanced strain accommodation. RSC Adv. 2013, 3 (3), 699-703.

[10] J. Z. Zhao, Z. L. Tao, J. Liang and J. Chen, Facile synthesis of nanoporous $\gamma-\mathrm{MnO}_{2}$ structures and their application in rechargeable Li-ion batteries. Cryst. Growth Des. 2008, 8 (8), 2799-2805. [11] C. X. Guo, M. Wang, T. Chen, X. W. Lou and C. M. Li, A Hierarchically nanostructured composite of $\mathrm{MnO}_{2}$ /conjugated polymer/graphene for high-performance lithium ion batteries. $A d v$. Energy Mater. 2011, 1 (5), 736-741.

[12] Y. Li, Q. Zhang, J. Zhu, X.-L. Wei and P. Shen, An extremely stable $\mathrm{MnO}_{2}$ anode incorporated with 3D porous graphene-like networks for lithium-ion batteries. J. Mater. Chem. A 2014, 2 (9), 3163-3168.

[13] J. Cabana, L. Monconduit, D. Larcher and M. R. Palacín, Beyond intercalation-based Li-ion batteries: the state of the art and challenges of electrode materials reacting through conversion reactions. Adv. Mater. 2010, 22 (35), E170-E192.

[14] Y. L. Ding, C. Y. Wu, H. M. Yu, J. Xie, G. S. Cao, T. J. Zhu, X. B. Zhao and Y. W. Zeng, Coaxial MnO/C nanotubes as anodes for lithium-ion batteries. Electrochim. Acta 2011, 56 (16), 5844-5848.

[15] B. Sun, Z. X. Chen, H. S. Kim, H. Ahn and G. X. Wang, MnO/C core-shell nanorods as high capacity anode materials for lithium-ion batteries. J. Power Sources 2011, 196 (6), 3346-3349.

[16] W. L. Yao, J. L. Wang, J. Yang and G. D. Du, Novel carbon nanofiber-cobalt oxide composites for lithium storage with large capacity and high reversibility. J. Power Sources 2008, 176 (1), 369-372. 
[17] L. J. Zhi, Y. S. Hu, B. El Hamaoui, X. Wang, I. Lieberwirth, U. Kolb, J. Maier and K. Müllen, Precursor-controlled formation of novel carbon/metal and carbon/metal oxide nanocomposites. Adv. Mater. 2008, 20 (9), 1727-1731.

[18] D. Qiu, Z. Xu, M. Zheng, B. Zhao, L. Pan and Y. Shi, Graphene anchored with mesoporous $\mathrm{NiO}$ nanoplates as anode material for lithium-ion batteries. J. Solid State Electrochem. 2012, 16 (5), 1889-1892.

[19] X. W. Lou, L. A. Archer and Z. C. Yang, Hollow micro-/nanostructures: synthesis and applications. Adv. Mater. 2008, 20 (21), 3987-4019.

[20] L. Xiao, D. Wu, S. Han, Y. Huang, S. Li, M. He, F. Zhang and X. Feng, Self-assembled $\mathrm{Fe}_{2} \mathrm{O}_{3}$ /graphene aerogel with high lithium storage performance. ACS Appl. Mater. Interfaces 2013, 5 (9), 3764-3769.

[21] L. Qian and L. Lu, Fabrication of three-dimensional porous graphene-manganese dioxide composites as electrode materials for supercapacitors. Colloids and Surfaces A: Physicochem. Eng. Aspects 2015, 465, 32-38.

[22] Z. Wu, S. Yang, Y. Sun, K. Parvez, X. Feng and K. Müllen, 3D nitrogen-doped graphene aerogel-supported $\mathrm{Fe}_{3} \mathrm{O}_{4}$ nanoparticles as efficient eletrocatalysts for the oxygen reduction reaction. J. Am. Chem. Soc. 2012, 134 (22), 9082-9085.

[23] C. Wang, H. Chen and S. Lu, Manganese oxide/graphene aerogel composites as an outstanding supercapacitor electrode material. Chem. Eur. J. 2014, 20 (2), 517-523.

[24] L. L. Zhang, X. Zhao, H. X. Ji, M. D. Stoller, L. F. Lai, S. Murali, S. McDonnell, B. Cleveger, R. M. Wallace and R. S. Ruoff, Nitrogen doping of graphene and its effect on quantum capacitance, and a new insight on the enhanced capacitance of N-doped carbon. Energy Environ. Sci. 2012, 5 (11), 9618-9625.

[25] Z.-H. Sheng, L. Shao, J.-J. Chen, W.-J. Bao, F.-B. Wang and X.-H. Xia, Catalyst-free synthesis of nitrogen-doped graphene via thermal annealing graphite oxide with melamine and its excellent electrocatalysis. ACS Nano 2011, 5 (6), 4350-4358.

[26] Wu, Z. S.; Ren, W.; Xu, L.; Li, F.; Cheng, H. M. Doped graphene sheets as anode materials with superhigh rate and large capacity for lithium ion batteries. ACS Nano 2011, 5 (7), 5463-5471. [27] L. Qie, W. Chen, Z. Wang, Q. Shao, X. Li, L. Yuan, X. Hu, W. Zhang and Y. Huang, Nitrogen-doped porous carbon nanofiber webs as anodes for lithium ion batteries with a superhigh 
capacity and rate capability. Adv. Mater. 2012, 24 (15), 2047-2050.

[28] C. Tan, J. Cao, A. Khattak, F. Cai, B. Jiang, G. Yang and S. Hu, High-performance tin oxide-nitrogen doped graphene aerogel hybrids as anode materials for lithium-ion batteries. $J$. Power Sources 2014, 207, 28-33.

[29] H. Yin, C. Zhang, F. Liu and Y. Hou, Hybrid of iron nitride and nitrogen-doped graphene aerogel as synergistic catalyst for oxygen reduction reaction. Adv. Funct. Mater. 2014, 24 (20), 2930-2937.

[30] L. Li, A. Raji and J. Tour, Graphene-wrapped $\mathrm{MnO}_{2}$-graphene nanoribbons as anode materials for high-performance lithium ion batteries. Adv. Mater. 2013, 25 (43), 6298-6302.

[31] H. Xia, M. Lai and L. Lu, Nanoflaky $\mathrm{MnO}_{2}$ /carbon nanotube nanocomposites as anode materials for lithium-ion batteries. J. Mater. Chem. 2010, 20 (33), 6896-6902.

[32] A. Yu, H. W. Park, A. Davies, D. C. Higgins, Z. Chen and X. Xiao, Free-standing layer-by-layer hybrid thin film of graphene- $\mathrm{MnO}_{2}$ nanotube as anode for lithium ion batteries. $J$. Phys. Chem. Lett. 2011, 2 (15), 1855-1860.

[33] W. S. Hummers and R. E. Offeman, Preparation of graphitic oxide. J. Am. Chem. Soc. 1958, 80 (6), 1339-1339.

[34] S.-Z. Zu and B.-H. Han, Aqueous dispersion of graphene sheets stabilized by Pluronic copolymers: Formation of supramolecular hydrogel. J. Phys. Chem. C 2009, 113 (31), 13651-13657.

[35] S. Chen, J. Duan, M. Jaroniec and S. Qiao, Three-dimensional N-doped graphene hydrogel/NiCo double hydroxide electrocatalysts for highly efficient oxygen evolution. Angew. Chem. Int. Ed. 2013, 52 (51), 13567-13570.

[36] G. Wang, L. Jia, Y. Zhu, B. Hou, D. Li and Y. Sun, Novel preparation of nitrogen-doped graphene in various forms with aqueous ammonia under mild conditions. RSC Advances 2012, 2 (30), 11249-11252.

[37] Y. X. Xu, K. X. Sheng, C. Li and G. Q. Shi, Self-assembled graphene hydrogel via a one-step hydrothermal process. ACS Nano 2010, 4 (7), 4324-4330.

[38] A. E. Fischer, K. A. Pettigrew, D. R. Rolison, R. M. Stroud and J. W. Long, Incorporation of homogeneous, nanoscale $\mathrm{MnO}_{2}$ within ultraporous carbon structures via self-limiting electroless deposition: implications for electrochemical capacitors. Nano Lett. 2007, 7 (2), 281-286. 
[39] B. Choi, M. Yang, W. Hong, J. Choi and Y. Huh, 3D macroporous graphene frameworks for supercapacitors with high energy and power densities. ACS Nano 2012, 6 (5), 4020-4028.

[40] Z.-Y. Sui, Q.-H. Meng, J.-T. Li, J.-H. Zhu, Y. Cui and B.-H. Han, High surface area porous carbons produced by steam activation of graphene aerogels. J. Mater. Chem. A 2014, 2 (25), 9891-9898.

[41] M. N. Patel, X. Q. Wang, B. Wilson, D. A. Ferrer, S. Dai, K. J. Stevenson and K. P. Johnston, Hybrid $\mathrm{MnO}_{2}$-disordered mesoporous carbon nanocomposites: synthesis and characterization as electrochemical pseudocapacitor electrodes. J. Mater. Chem. 2010, 20 (2), 390-398.

[42] L. Sun, C. Tian, Y. Fu, Y. Yang, J. Yin, L. Wang and H. Fu, Nitrogen-doped porous graphitic carbon as an excellent electrode material for advanced supercapacitors. Chem. Eur. J. 2014, 20 (2), 564-574.

[43] Z. Li, Y. Mi, X. Liu, S. Liu, S. Yang and J. Wang, Flexible graphene/ $\mathrm{MnO}_{2}$ composite papers for supercapacitor electrodes. J. Mater. Chem. 2011, 21 (38), 14706-14711.

[44] Z.-Y. Sui, Y. Cui, J.-H. Zhu and B.-H. Han, Preparation of three-dimensional graphene oxide-polyethylenimine porous materials as dye and gas adsorbents. ACS Appl. Mater. Interfaces 2013, 5 (18), 9172-9179.

[45] D. Sung, J. Gunjakar, T. Kim, I. Kim, Y. Lee and S. Hwang, Graphene-assisted room-temperature synthesis of 2D nanostructured hybrid electrode materials: dramatic acceleration of the formation rate of $2 \mathrm{D}$ metal oxide nanoplates induced by reduced graphene oxide nanosheets. Chem. Eur. J. 2013, 19 (22): 7109-7117.

[46] Y. Lee, I. Kim, T. Kim, J. Lee and S. Hwang, Mixed colloidal suspensions of reduced graphene oxide and layered metal oxide nanosheets: useful precursors for the porous nanocomposites and hybrid films of graphene/metal oxide. Chem. Eur. J. 2012, 18 (8), 2263-2271. [47] K. Shu, C. Y. Wang, M. Wang, C. Zhao and G. G. Wallace, Graphene cryogel papers with enhanced mechanical strength for high performance lithium battery anodes. J. Mater. Chem. A 2014, 2 (5), 1325-1331.

[48] Y. Yang, C. Y. Wang, B. B. Yue, S. Gambhir, C. Too and G. G. Wallace, Electrochemically synthesized polypyrrole/graphene composite film for lithium batteries. Adv. Energy Mater. 2012, 2 (2), 266-272.

[49] Y. Sun, X. Hu, W. Luo, F. Xia and Y. Huang, Reconstruction of conformal nanoscale MnO on 
graphene as a high-capacity and long-life anode material for lithium ion batteries. Adv. Funct. Mater. 2013, 23 (19), 2436-2444. 


\section{Table of Contents/Abstract Graphic}

$\mathrm{MnO}_{2} /$ nitrogen-doped graphene aerogels prepared via a redox process between $\mathrm{KMnO}_{4}$ and carbon demonstrate excellent electrochemical properties in Li-ion batteries.

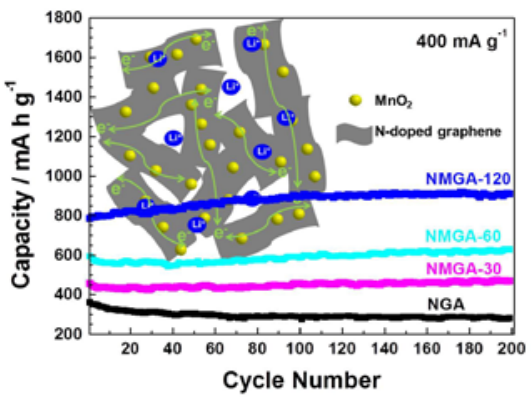

